\title{
Model Policy Guidelines for Opioid Addiction Treatment in the Medical Office
}

\author{
Report of the Center for Substance Abuse Work Group, Federation of State Medical Boards
}

The following recommendations were adopted as policy by the House of Delegates of the Federation of State Medical Boards of the United States in April 2002.

\section{INTRODUCTION}

On October 17,2000, "The Children's Health Act of 2000" (HR 4365) was signed into federal law. Section 3502 of that Act sets forth the "Drug Addiction Treatment Act of 2000" (DATA). This legislation is of particular interest to state medical boards because it provides for significant changes in the oversight of the medical treatment of opioid addiction. For the first time in almost a century, physicians may treat opioid addiction with opioid medications in office-based settings. These opioid medications, Schedules III, IV, and V opioid drugs with Food and Drug Administration (FDA) approved indication for the treatment of opioid dependence, may be provided to patients under certain restrictions. This new treatment modality makes it possible for physicians to treat patients for opioid addiction with these Schedules III-V narcotic controlled substances specifically approved by the FDA for addiction treatment in their offices without the requirement that they be referred to specialized opioid treatment programs (OTP's) as previously required under federal law.

The DATA requires changes in the oversight systems within the Department of Health and Human Services (HHS) and the Drug Enforcement Administration (DEA). The Secretary of HHS has delegated authority in this area to the

The Model Policy Guidelines for Opioid Addiction Treatment in the Medical Office was produced by the Center for Substance Abuse Work Group. This article is reprinted with permission of the Federation of State Medical Boards, for educational purposes, from the Journal of Medical Licensure and Discipline, 2003; 89: 35-42. Members of the Work Group are listed at the end of this article.
Center for Substance Abuse Treatment (CSAT), within the Substance Abuse and Mental Health Services Administration (SAMHSA). Bringing the treatment of opioid addicted patients into the scope of individual physician practice significantly increases the role of the state medical board in overseeing opioid addiction treatment. For this reason, the Federation of State Medical Boards entered into an agreement with CSAT to develop model guidelines for use by state medical boards in regulating the office-based treatment of opioid addiction.

The following model guidelines are designed to encourage state medical boards to adopt consistent standards, promote public health by availing opioid addicted patients of appropriate treatment, and educating the regulatory and physician communities on new treatment modalities offering an alternative in the treatment of opioid addiction.

\section{Section I: Preamble}

The (name of board) recognizes that the prevalence of addiction to heroin and other opioids has risen sharply in the United States and that the residents of the State of (name of state) should have access to modern, appropriate and effective addiction treatment. The appropriate application of up-to-date knowledge and treatment modalities can successfully treat patients who suffer from opioid addiction and reduce the morbidity, mortality and costs associated with opioid addiction, as well as public health problems such as HIV, HBV, HCV and other infectious diseases. The Board encourages all physicians to assess their patients for a history of substance abuse and potential opioid addiction. The Board has developed these guidelines in an effort to balance the need to expand treatment capacity for opioid addicted patients with the need to prevent the inappropriate, unwise or illegal prescribing of opioids.

Until recently, physicians have been prohibited from prescribing and dispensing opioid medications in the treatment of opioid addiction, except within the confines of federally regulated opioid treatment programs. Because of the increasing number of opioid-addicted individuals and the associated public health problems, as well as the limited availability of addiction treatment programs, federal laws now enable qualified physicians to prescribe Schedule III-V medications approved by the Food and Drug Administration for office-based treatment of opioid addiction $1(1)$.

Physicians who consider officebased treatment of opioid addiction must be able to recognize the condition of drug or opioid addiction and be knowledgeable about the appropriate use of opioid agonist, antagonist, and partial agonist medications. Physicians must also demonstrate required qualifications as defined under and in accordance with the "Drug Addiction Treatment Act of 2000" (DATA) (Public Law 106-310, Title XXXV, Sections 3501 and 3502) and obtain a waiver from the Substance Abuse and Mental Health Services Administration (SAMHSA), as authorized by the Secretary of HHS. In order to qualify for a waiver, physicians must hold a current license in the State of (name of state) and, at a minimum, meet one or more of the following 
conditions to be considered as qualified to treat opioid addicted patients in an officebased setting in this state:

- Subspecialty board certification in addiction psychiatry from the American Board of Medical Specialties

- Subspecialty board certification in addiction medicine from the American Osteopathic Association

- Addiction certification from the American Society of Addiction Medicine

- Completion of not less than 8 hours of training related to the treatment and management of opioid-dependent patients provided by the American Society of Addiction Medicine, the American Academy of Addiction Psychiatry, the American Medical Association, the American Osteopathic Association, the American Psychiatric Association, or other organization approved by the board.

- Participation as an investigator in one or more clinical trials leading to the approval of a narcotic drug in Schedule III, IV, or $\mathrm{V}$ or a combination of such drugs for treatment of opioid addicted patients (must be evidenced by a statement submitted to the Secretary of Health and Human Services by the sponsor of such approved drug).

- Additional qualification criteria may be added through legislative enactment.

In addition to the waiver, physicians must have a valid DEA registration number and a DEA identification number that specifically authorizes such office-based treatment.

The waiver to provide addiction treatment under DATA is granted by the Secretary of HHS, presumably through SAMHSA, no later than 45 days after receipt of the physician's written notification. Upon request from SAMHSA, the Attorney General, presumably through DEA, will automatically assign the physician an identification number that will be used with the physician's DEA registration number. However, if SAMHSA has not acted on the physician's request for a waiver by the end of this 45-day period, DEA will automatically assign the physician an identification number.

Furthermore, if a physician wishes to prescribe or dispense narcotic drugs for maintenance or detoxification treatment on an emergency basis in order to facilitate the treatment of an individual patient before the 45 -day waiting period has elapsed, the physician musty notify SAMHSA and the DEA of the physician's intent to provide such treatment.

The Board recognizes that new treatment modalities offer an alternative in the treatment of opioid addiction. Based on appropriate patient assessment and evaluation, it may be both feasible and desirable to provide office-based treatment of opioid addicted patients with Schedules III-V opioid medications approved for such use by the FDA and regulated in such use by Center for Substance Abuse Treatment (CSAT)/SAMHSA. Physicians are referred to the Buprenorphine Clinical Practice Guidelines, available at the CSAT/SAMHSA, Office of Pharmacologic and Alternative Therapies, Rockwall II, Room 7-222, 5515 Security Lane, 5600 Fishers Lane, Rockville, MD 20857; (301) 443-7614 or http://www.samhsa.gov/ centers/csat/opat.html.

The medical recognition and management of opioid addiction should be based upon current knowledge and research and includes the use of both pharmaceutical and non-pharmaceutical modalities. Prior to initiating treatment, physicians should be knowledgeable about addiction treatment and all available pharmacologic treatment agents as well as available ancillary services to support both the physician and patient. In order to undertake treatment of opioid addicted patients, in accordance with these guidelines, physicians must demonstrate a capacity to refer patients for appropriate counseling and other ancillary services.

The (state medical board) is obligated under the laws of the State of (name of state) to protect the public health and safety. The Board recognizes that inappropriate prescribing of controlled substances, including opioids, may lead to drug diversion and abuse by individuals who seek them for other than legitimate medical use. Physicians must be diligent in preventing the diversion of drugs for illegitimate and nonmedical uses.

Qualified physicians need not fear disciplinary action from the Board or other state regulatory or enforcement agency for appropriate prescribing, dispensing or administering approved opioid drugs in Schedules III, IV, or V, or combinations thereof, for a legitimate medical purpose in the usual course of opioid addiction treatment. The Board will consider appropriate prescribing, ordering, administering, or dispensing of these medications for opioid addiction to be for a legitimate medical purpose if based on accepted scientific knowledge of the treatment of opioid addiction and in compliance with applicable state and federal law.

The Board will determine the appropriateness of prescribing based on the physician's overall treatment of the patient and on available documentation of treatment plans and outcomes. The goal is to document and treat the patient's addiction while effectively addressing other aspects of the patient's functioning, including physical, psychological, medical, social and work-related factors. The following guidelines are not intended to define complete or best practice, but rather to communicate what the Board considers to be within the boundaries of accepted professional practice.

\section{Section II: Guidelines}

The Board has adopted the following guidelines when evaluating the documentation and treatment of opioid addiction under DATA:

Compliance with Controlled Substances Laws and Regulations

Generally, to prescribe and dispense Schedules III-V opioid medications for the treatment of opioid addiction under DATA, the physician must be licensed in the state, have a valid DEA controlled substances registration and identification number, comply with federal and state regulations applicable to controlled substances, and have a current waiver issued by SAMHSA. To obtain this waiver, the physician must submit written notification to the Secretary of HHS of their intent to provide this treatment modality, certifying the physician's qualifications and listing his/her DEA registration number. SAMHSA will then notify DEA whether a waiver has been granted. If SAMHSA grants the physician a waiver, DEA will issue the qualifying physician an identification number. In addition to these requirements, the DATA limits the number of patients that a physician or a group practice is permitted to treat to 30 . This numerical limitation may be changed by regulation in the future.

Physicians are specifically prohibited from delegating prescribing opioids for detoxification and/or maintenance treatment purposes to non-physicians. Physicians are referred to DEA regulations (21CFR, Part 1300 to end) and the DEA 
Physician's Manual www.deadiversion.us doj.gov and (any relevant documents issued by the state medical board) for specific rules governing issuance of controlled substances prescriptions as well as applicable state regulations.

\section{Evaluation of the Patient}

A recent, complete medical history and physical examination must be documented in the medical record. The medical record should document the nature of the patient's addiction(s), evaluate underlying or coexisting diseases or conditions, the effect on physical and psychological function, and history of substance abuse and any treatments therefor. The medical record should also document the suitability of the patient for office-based treatment based upon recognized diagnostic criteria(2).

DSM-IV-TR Substance Dependence Criteria(3)

A maladaptive pattern of substance use, leading to clinically significant impairment or distress, as manifested by three (or more) of the following, occurring at any time in the same 12-month period:

- tolerance, as defined by either of the following:

- a need for markedly increased amounts of the substance to achieve intoxication or desired effect, or

- markedly diminished effect with continued use of the same amount of the substance

- withdrawal, as manifested by either of the following:

- the characteristic withdrawal syndrome for the substance, or

- the same (or closely related) substance is taken to relieve or avoid withdrawal symptoms

- the substance is often taken in larger amounts or over longer period than was intended

- there is a persistent desire or unsuccessful efforts to cut down or control substance use

- a great deal of time is spent in activities necessary to obtain the substance (e.g., visiting multiple doctors or driving long distances), use the substance (e.g., chain-smoking), or recover from its effects

- important social, occupational or recreational activities are given up or reduced because of substance use the substance use is continued despite knowledge of having a persistent or recurrent physical or psychological problem that is likely to have been caused or exacerbated by the substance (e.g., current cocaine use despite recognition of cocaineinduced depression, or continued drinking despite recognition that an ulcer was made worse by alcohol consumption)

\section{Treatment Plan}

The written treatment plan should state objectives that will be used to determine treatment success, such as freedom from intoxication, improved physical function, psychosocial function and compliance and should indicate if any further diagnostic evaluations are planned, as well as counseling, psychiatric management or other ancillary services. This plan should be reviewed periodically. After treatment begins, the physician should adjust drug therapy to the individual medical needs of each patient. Treatment goals, other treatment modalities or a rehabilitation program should be evaluated and discussed with the patient. If possible, every attempt should be made to involve significant others or immediate family members in the treatment process, with the patient's consent. The treatment plan should also contain contingencies for treatment failure (i.e., due to failure to comply with the treatment plan, abuse of other opioids, or evidence that the Schedules III-V medications are not being taken).

Informed Consent and Agreement for Treatment

The physician should discuss the risks and benefits of the use of these approved opioid medications with the patient and, with appropriate consent of the patient, significant other(s), family members, or guardian. The patient should receive opioids from only one physician and/or one pharmacy when possible. The physician should employ the use of a written agreement between physician and patient addressing such issues as (1) alternative treatment options; (2) regular toxicologic testing for drugs of abuse and therapeutic drug levels (if available and indicated); (3) number and frequency of all prescription refills; and (4) reasons for which drug therapy may be discontinued (i.e.; violation of agreement).
Periodic Patient Evaluation

Patients should be seen at reasonable intervals (at least weekly during initial treatment) based upon the individual circumstance of the patient. Periodic assessment is necessary to determine compliance with the dosing regimen, effectiveness of treatment plan, and to assess how the patient is handling the prescribed medication. Once a stable dosage is achieved and urine (or other toxicologic) tests are free of illicit drugs, less frequent office visits may be initiated (monthly may be reasonable for patients on a stable dose of the prescribed medication(s) who are making progress toward treatment objectives). Continuation or modification of opioid therapy should depend on the physician's evaluation of progress toward stated treatment objectives such as (1) absence of toxicity; (2) absence of medical or behavioral adverse effects; (3) responsible handling of medications; (4) compliance with all elements of the treatment plan (including recovery-oriented activities, psychotherapy and/or other psychosocial modalities); and (5) abstinence from illicit drug use. If reasonable treatment goals are not being achieved, the physician should reevaluate the appropriateness of continued treatment.

\section{Consultation}

The physician should refer the patient as necessary for additional evaluation and treatment in order to achieve treatment objectives. The physician should pursue a team approach to the treatment of opioid addiction, including referral for counseling and other ancillary services. Ongoing communication between the physician and consultants is necessary to ensure appropriate compliance with the treatment plan. This may be included in the formal treatment agreement between the physician and patient. Special attention should be given to those patients who are at risk for misusing their medications and those whose living or work arrangements pose a risk for medication misuse or diversion. The management of addiction in patients with comorbid psychiatric disorders requires extra care, monitoring, documentation and consultation with or referral to a mental health professional.

\footnotetext{
Medical Records

The prescribing physician should keep accurate and complete records to in-
} 
clude (1) the medical history and physical examination; (2) diagnostic, therapeutic and laboratory results; (3) evaluations and consultations; (4) treatment objectives; (5) discussion of risks and benefits; (6) treatments; (7) medications (including date, type, dosage, and quantity prescribed and/or dispensed to each patient); (8) a physical inventory of all Schedules III, IV, and V controlled substances on hand that are dispensed by the physician in the course of maintenance or detoxification treatment of an individual; (9) instructions and agreements; and (10) periodic reviews. Records should remain current and be maintained in an accessible manner and readily available for review. The physician must adhere to the special confidentiality requirements of $42 \mathrm{CFR}$, Part 2, which apply to the treatment of drug and alcohol addiction, including the prohibition against release of records or other information, except pursuant to a proper patient consent or court order in full compliance with 42CFR2, or the Federal or State officials listed in 42CFR2, or in cases of true medical emergency or for the mandatory reporting of child abuse.

\section{Section III: Definitions}

For the purposes of these guidelines, the following terms are defined as follows:

Addiction: A primary, chronic, neurobiologic disease, with genetic, psychosocial, and environmental factors influencing its development and manifestations. It is characterized by behaviors that include one or more of the following: impaired control over drug use, compulsive use, continued use despite harm and craving.

Agonists: Agonist drugs are substances that bind to the receptor and produce a response that is similar in effect to the natural ligand that would activate it. Full mu opioid agonists activate mu receptors, and increasing doses of full agonists produce increasing effects. Most opioids that are abused, such as morphine and heroin are full mu opioid agonists.

"Approved Schedule III-V Opioids": Opioids referred to by the DATA, specifically approved by the FDA for treatment of opioid dependence or addiction.

Antagonists: Antagonists bind to but do not activate receptors. They prevent the receptor from being activated by an agonist compound. Examples of opioid antagonists are naltrexone and naloxone.
Maintenance Treatment: Maintenance treatment means the dispensing for a period in excess of 21 days of an opioid medication(s) at stable dosage levels in the treatment of an individual for dependence upon heroin or other morphinelike drugs.

Opioid Dependence: A maladaptive pattern of substance use, leading to clinically significant impairment or distress, manifested by 3 or more of the following, occurring at any time in the same 12month period:

- A need for markedly increased amounts of the substance to achieve intoxication or desired effect or markedly diminished effect with continued use of the same amount of substance;

- The characteristic withdrawal syndrome for the substance or the same (or closely related) substance is taken to relieve or avoid withdrawal symptoms;

- The substance was taken in larger amounts or over a longer period of time than was intended;

- There is a persistent desire or unsuccessful efforts to cut down or control substance use;

Significant time is spent on activities to obtain the substance, use the substance, or recover from its effects; Important social, occupational, or recreational activities are discontinued or reduced because of substance use;

- Substance use is continued despite knowledge of having a persistent physical or psychological problem that is caused or exacerbated by the substance.

Opioid Drug: Opioid drug means any drug having an addiction-forming or addiction-sustaining liability similar to morphine or being capable of conversion into a drug having such addiction-forming or addiction sustaining liability (this is referred to as an opiate in the Controlled Substances Act).

Opioid Treatment Program (OTP) (sometimes referred to as a methadone clinic or narcotic treatment program): Opioid treatment program means a licensed program or practitioner engaged in the treatment of opioid addicted patients with approved Scheduled II opioids (methadone and/or LAAM).
Partial Agonists: Partial agonists occupy and activate receptors. At low doses, like full agonists, increasing doses of the partial agonist produce increasing effects. However, unlike full agonists, the receptor-activation produced by a partial agonist reaches a plateau over which increasing doses do not produce an increasing effect. The plateau may have the effect of limiting the partial agonist's therapeutic activity as well as its toxicity. Buprenorphine is an example of a partial agonist.

Physical Dependence: A state of adaptation that is manifested by a drug class specific withdrawal syndrome that can be produced by abrupt cessation, rapid dose reduction, decreasing blood level of the drug, and/or administration of an antagonist.

Qualified Physician: A physician, licensed in the State of (name of state) who holds a current waiver issued by SAMHSA (as authorized by the Secretary of HHS) and meets one or more of the conditions set forth in Section 1. In addition, a physician must have a valid DEA registration and identification number authorizing the physician to conduct office-based treatment.

Substance Abuse: A maladaptive pattern of substance use leading to clinically significant impairment or distress, as manifested by one or more of the following, occurring within a 12-month period:

Recurrent substance use resulting in a failure to fulfill major role obligations at work, school, or home;

- Recurrent substance use in situations in which it is physically hazardous;

Recurrent substance-related legal problems;

- Continued substance use despite having persistent or recurrent social or interpersonal problems caused or exacerbated by the effects of the substance.

Tolerance: A state of adaptation in which exposure to a drug induces changes that result in diminution of one or more of the drug's effects over time.

Waiver: A documented authorization from the Secretary of HHS issued by SAMHSA under the DATA that exempts qualified physicians from the rules applied to OTPs. Implementation of the waiver includes possession of a valid DEA certificate with applicable suffix. 
REFERENCES

1. Drug Addiction Treatment Act of 2000, Public Law 106-310, Title XXXV, Section 3501 and 3502.

2. Buprenorphine Clinical Practice Guidelines, Table 3-1.
3. American Psychiatric Association, Diagnostic and Statistical Manual of Mental Disorders, 4th ed., Text Revision, Washington, D.C.

\section{CENTER FOR SUBSTANCE ABUSE WORK GROUP:}

The Federation of State Medical Boards recognizes CSAT for initiating this project and cooperating in the development of the guidelines. The Federation also acknowledges the efforts of the following individuals who participated in the workgroup that provided direction to this project:

George C. Barrett, MD

Immediate Past President, Federation

of State Medical Boards

Regina M. Benjamin, MD, MBA

Alabama State Board of Medical Examiners

Jack Blaine, MD

National Institute on Drug Abuse

W. Joseph Burnett, MD,

Director, Executive Director, Mississip-

pi State Board of Medical Licensure

Carlos Campos, MD, MPH

Former Member, Texas State Board of

Medical Examiners

Charles Cichon

President, National Association of

Drug Diversion Investigators

Dorynne Czechowicz, MD

Division of Treatment Research and

Development

National Institute on Drug Abuse

Stephen L. Dilts, MD, PhD

President, American Academy of Ad-

diction Psychiatry/American Medical

Association

William H. Fleming, III, MD

Texas State Board of Medical Examiners

\section{Patricia M. Good}

Chief, Liaison and Policy Section/

Office of Diversion Control

Drug Enforcement Administration

William L. Harp, MD

Executive Director, Virginia Board of Medicine

D. Christopher Keyes, MD, MPH

Chief, Section of Toxicology, Division

of Emergency Medicine

University of Texas Southwestern Med-

ical School at Dallas

\section{Walter Ling, MD}

Director, UCLA Integrated Substance

Abuse Programs

Ira Lubell, MD

Santa Clara Valley Medical Center

James J. Manlandro, DO

President, American Osteopathic

Academy of Addiction Medicine

Tom McGinnis, Director

Pharmacy Affairs, Office of Policy, U.S.

Food and Drug Administration

Laura F. McNicholas, MD, PhD

Chair, CSAT Clinical Guidelines Con-

sensus Panel on Buprenorphine

Rev. Daniel W. Morrissey, OP

Director-at-large, Federation of State

Medical Boards
Richard T. Suchinsky, MD

Associate Director for Addictive Dis-

orders

Veterans Health Administration

\section{R. Russell Thomas, Jr., DO, MPH}

Texas State Board of Medical Examiners

Alan Trachtenberg, MD, MPH

Medical Director, SAMHSA/CSAT/

OPAT

George J. Van Komen, MD

President, Federation of State Medical Boards

Donald R. Wesson, MD

American Society of Addiction Medicine

Donald H. Williams

National Association of Boards of

Pharmacy

\section{Federation Staff:}

Bruce A. Levy, MD, JD

Deputy Executive Vice President

Federation of State Medical Boards

\section{Lisa Robin}

Director, Leadership Support Service

Federation of State Medical Boards

Jeanne Hoferer

Legislative Services

Federation of State Medical Boards 
